\title{
PROCESSO DE SIGNIFICAÇÃO NO TRABALHO PARA TRABALHADORES ARTESANAIS ATUANDO EM UMA CAPITAL DO NORDESTE BRASILEIRO
}

\author{
PROCESO DE SIGNIFICACIÓN EN EL TRABAJO PARA \\ TRABAJADORES ARTESANALES ACTUANDO EN UNA CAPITAL DEL \\ NORDESTE BRASILENOO
MEANING PROCESS AT WORK FOR ARTISAN WORKERS ACTING IN A CAPITAL CITY OF THE BRAZILIAN NORTHEAST

\author{
Daniel Santos de Carvalho ${ }^{1}$ e Pedro Bendassolli ${ }^{2}$ \\ ${ }^{1}$ Universidade Potiguar, Rio Grande do Norte, Natal/RN, Brasil \\ ${ }^{2}$ Universidade Federal do Rio Grande do Norte, Natal/RN, Brasil
}

\begin{abstract}
RESUMO: O objetivo desta investigação é contribuir para uma compreensão do processo de significação no trabalho para trabalhadores artesanais em uma capital do Nordeste brasileiro. Tal processo é definido como a articulação entre significados e sentidos mediados pela atividade concreta. Participaram 20 artesãos atuando em distintos ramos da atividade artesanal e com uma média de 16 anos de trabalho nesse setor. As informações foram obtidas por meio de entrevistas, conduzidas por meio de conceitos sensitivos associados ao processo de significação, e por produção fotográfica, pelo próprio participante, acerca de sua atividade. Os resultados indicam, no tocante às entrevistas, três grandes eixos de significados: um relativo à integração do trabalho à vida e à família; outro associado à criação e produção; e um terceiro referente às relações interpessoais e impessoais. As fotografias trouxeram à cena um elemento central à construção do sentido: a criatividade e implicação com o trabalho.
\end{abstract}

PALAVRAS-CHAVE: Processo de significação; Trabalho; Artesanato.

RESUMEN: El objetivo de esta investigación es contribuir a una comprensión del proceso de significación en el trabajo para trabajadores artesanales en una capital del Nordeste brasileño. Este proceso se define como la articulación entre significados y sentidos mediados por la actividad concreta. Participaron 20 artesanos actuando en distintas ramas de la actividad artesanal y con una media de 16 años de trabajo en ese sector. Las informaciones fueron obtenidas por medio de entrevistas, conducidas por medio de conceptos sensitivos asociados al proceso de significación, y por producción fotográfica, por el propio participante, acerca de su actividad. Los resultados indi-cam, en cuanto a las entrevistas, tres grandes ejes de significados: uno relativo a la integración del trabajo a la vida ya la familia; Otro asociado a la creación y producción; Y un tercero referente a las relaciones interpersonal e impersonal. Las fotografías trajeron a la escena un elemento central a la construcción del sentido: la creatividad y la implicación con el trabajo.

PALABRAS CLAVE: Procedimiento de significación; Trabajo; Artesanato.

ABSTRACT: The objective of this research is to contribute to an understanding of the process of signification in the work for artisanal workers in a capital city of the Northeast of Brazil. Such a process is defined as the articulation between meanings and senses mediated by concrete activity. Twenty artisans participated in different branches of artisanal activity and with an average of 16 years of work in this sector. The information was obtained through interviews, conducted through sensory concepts associated with the process of signification, and by the participant's photographic production of his activity. The results indicate, in terms of interviews, three main axes of meanings: one concerning the integration of work into life and the family; Another associated with creation and production; And a third concerning interpersonal and impersonal relations. The photographs brought to the scene a central element in the construction of meaning: creativity and involvement with work.

KEYWORDS: Meaning process; Work; Craftmanship. 


\section{Introdução}

Muito certamente você já deve ter visto, ouvido falar ou adquirido algum produto artesanal em sua vida. Talvez você o tenha encontrado em uma viagem, talvez o tenha adquirido como uma peça decorativa, ou até mesmo como um recurso para o uso no dia a dia. Ele pode se apresentar de maneira simples, sendo produzido com poucos elementos e com insumos facilmente encontrados e pouco onerosos, ou ser pomposo, requintado, uma iguaria luxuosa, única em seu preço e/ou valor. Os produtos artesanais podem se apresentar de diversas formas, e a atividade que o fundamenta é uma das formas de trabalho mais antigas, conhecida e empreendida pelo homem.

$\mathrm{Na}$ atualidade, a atividade artesanal é, ademais, uma importante fonte de desenvolvimento econômico, fazendo girar cerca de cinquenta bilhões de reais anualmente no Brasil, segundo dados do portal da Empresa Brasileira de Comunicação - EBC, o que corresponde, diretamente, a uma média de 7 a $8 \%$ do PIB do país. A EBC aponta ainda que, se olharmos para a distribuição da produção e comercialização artesanal dentro do país, as participações mais fortes concentram-se nas regiões Norte e Nordeste, cerca de $65 \%$ da produção de todo o país. Pela sua importância, trata-se de uma temática de interesse social e acadêmico, e daí a necessidade de se refletir sobre ela, suas formas de desenvolvimento, influência social e sua própria constituição dentro dos modelos trabalhistas e de mercado. O trabalho artesanal é, como a expressão o sugere, um trabalho, apontando que há mais em nossa compreensão sobre seu sentido que a ideia de emprego ou ocupação levam-nos a pensar.

De fato, para além de seu sentido e função como emprego, o trabalho é uma atividade central no processo de subjetivação humana, atuando como fonte de autorrealização, de experiências psicossociais e de sentido para a vida (Ribeiro \& Léda, 2009). Durante o decorrer do tempo, várias foram as designações sociais atribuídas a ele, variando de sofrimento, punição, penalidade, até criação, obra e construção de riquezas (Meaning of Work International Research Team [MOW ], 1987). Com a emergência da modernidade, contudo, a configuração socioeconômica que mais influenciou na compreensão que até hoje temos do trabalho foi o capitalismo.

Com sua dominância iniciada em meados do século XVI, esse sistema econômico, aliado ao desenvolvimento industrial e tecnológico, transformou a força de trabalho em mercadoria para produzir mais-valia (Alves, 2007). Desse modo, conforme se conhece de análises como as de Marx (1989), por exemplo, o trabalho se organiza, no capitalismo, de maneira que suas ações sejam desenvolvidas a partir da compra e venda da força humana disposta e sujeita ao assalariamento. Contudo, essa configuração não é plenamente hegemônica, convivendo com formas autônomas ou semiautônomas de desenvolvimento do trabalho. Uma delas, quase tão antiga quanto a própria humanidade, é o trabalho artesanal, como já comentado.

No espaço do capitalismo, o artesão tende a produzir e comercializar seus produtos e a se comportar frente ao "cliente" conforme os moldes e padrões instituídos pelo mercado de bens e serviços (Oliveira, 2010). Com isso, podem-se criar zonas de tensão, sobreposição ou ambiguidade entre o trabalho artesanal, para alguns autores tomado como protótipo do próprio trabalho (Marx, 1989), formas precárias de trabalho e desemprego, e o próprio trabalho assalariado (emprego formal). Reconhecendo a complexidade dessas aproximações, este artigo toma como fenômeno a interseção entre trabalho artesanal e a 
dinâmica do trabalho sob condições capitalistas. Para isso, baseia-se em pesquisa empírica com artesãos atuando em uma capital do Nordeste brasileiro. Em termos teóricos, entra nesse universo a partir de um recorte que privilegia o processo significação no trabalho, o qual é definido na sequência, juntamente com uma análise teórica mais detida sobre a atividade artesanal.

\section{O processo de significação do trabalho}

O processo de significação no trabalho pode ser definido como a relação de interdependência entre sentido-significado na dinâmica de constituição pessoal, baseada na interação com a atividade de trabalho, considerando as determinações contextuais e o jogo interno de sujeição e pessoalização por ela mobilizados (Bendassolli \& Gondim, 2014; Clot, 1999, 2008). É constituído de três elementos: significados, sentidos e sua mobilização em uma atividade concreta.

"Significados" dizem respeito aos signos compartilhados por um coletivo, e têm uma função decisiva nos processos de comunicação, pois implicam na relativa convergência de interpretações acerca dos objetos compartilhados da experiência. No campo específico do trabalho, uma pesquisa realizada nos anos de 1980, e que veio a ser conhecida como Work International Research Team, ou MOW (1987), define os significados do trabalho como um construto psicológico móvel e ativo, estruturado por meio de múltiplas dimensões, que se elaboram através da interação entre variáveis do ambiente e relacionadas às pessoas, sendo também influenciado pelas transformações do trabalho ao longo do tempo (MOW, 1987).

De modo geral, os significados remetem ao compartilhamento de signos em uma determinada cultura. Como afirmam Bendassolli e Gondim (2014), as pesquisas inspiradas pelo MOW "propõem a identificação de diversos padrões de significados, estabilizados provisoriamente na cultura, os quais agem como narrativas compartilhadas a respeito do valor, do papel, do propósito, e da finalidade do trabalho na vida humana” (p. 132). Nesse nível dos significados, as pessoas tenderiam a uma convergência no que diz respeito a um objeto social - neste caso, o trabalho. Por exemplo, o compreendendo como fonte de renda, como forma de realização, como meio de ocupar o tempo, entre outros significados amiúde identificados por pesquisas inspiradas na captura dos elementos gerais e coletivos associados ao trabalho.

Contudo, a experiência do sujeito com o trabalho não se resume apenas aos significados recebidos coletivamente, por meio das práticas culturais. Ele também possui sentido, isto é, abre-se a uma dimensão pessoal, singular. "Sentidos" referem-se, pois, ao processo pelo qual as pessoas apropriam-se dos significados gerais e os transformam, reproduzem ou inovam a partir de sua experiência concreta. "Sentidos" referem-se à dimensão pessoal e singular do processo de significação.

Em termos de raízes teóricas, essa forma de conceber as facetas do processo de significação remete à obra de Vygotsky (1998), autor que propõe uma distinção entre significados e sentidos. Enquanto os primeiros remetem ao que é estabilizado na linguagem, pelo compartilhamento de signos, os sentidos referem-se ao processo pelo qual o indivíduo internaliza aqueles significados, os reelabora e os externaliza na forma de outros signifi- 
cados a serem então culturalmente compartilhados. Os sentidos estão, para Vygotsky, em íntima relação com a memória, os afetos e as experiências singulares (Aguiar \& Ozella, 2006; Vygotsky, 1998). Porém, um terceiro elemento é fundamental para a realização do processo de internalização-externalização da unidade sentido-significados, a saber: a atividade.

A "atividade" corresponde ao modo como o sujeito, por meio de signos (linguagem, significados) e de ferramentas (instrumentos), opera sobre partes do "real" tendo em vista o alcance de determinados objetivos. A atividade é uma ação orientada por um propósito, realizando mudanças tanto no sujeito quanto na realidade (Bulgacov, Camargo, Canopf, Matos, \& Bevervançozdepski, 2014). Na bibliografia centrada em torno das "teorias da atividade", a atividade, na linha aberta por Vygotsky, é compreendida como forma de mediação (Engeström, 1987) entre o sujeito e o mundo (ou entre sujeito-objeto, ou o "real"), por meio da qual, para resgatar Leontiev (1978), se desenvolve a própria consciência. Conforme sumariza Bulgacov et al. (2014), baseando-se em Leontiev, "a estrutura da atividade [constitui-se] das necessidades humanas, dos seus motivos, propósitos e condições. Através da atividade, o homem não apenas se relaciona com o mundo, mas o produz e é produzido por ele” (p. 4).

Entendendo agora as características de cada um dos elementos constituintes do processo de significação, partimos para a compreensão de como tais construtos se relacionam ativamente. Bendassolli e Coelho-Lima (2015) apresentam um modelo teórico que se detém a interpretar a interrelação mencionada, tal como vemos na Figura1.

\section{Figura 1: Modelo teórico do processo de significação}

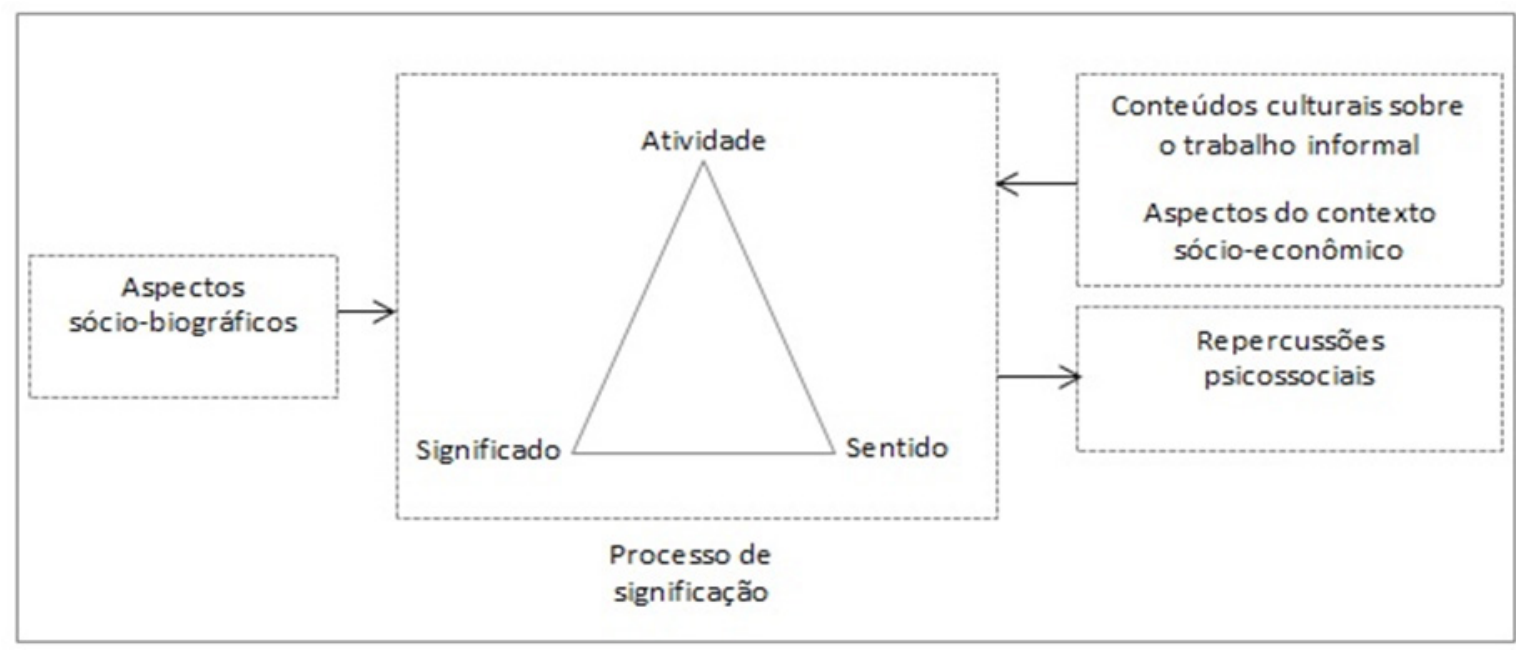

Fonte: Bendassolli, P. F., \& Coelho-Lima, F. (2015). Psicologia e trabalho informal: A perspectiva dos processos de significação. Psicologia \& Sociedade, 27(2).

Em meio à discussão que se segue, o modelo apresentado na Figura 1 refere-se a uma forma de pensar a processualidade entre atividade, sentidos e significados. Os elementos externos à tríade central do modelo irão aqui subsidiar uma reflexão a respeito de algumas contribuições do contexto para o entendimento do fenômeno investigado. 


\section{O trabalho artesanal}

Ao longo do tempo, o fazer artesanal esteve fortemente ligado à interação direta com alguma espécie de matéria-prima ao alcance do artesão, em uma integração entre processo e produto de trabalho. Araújo (2014) discute o papel de filósofos como Aristóteles no desenvolvimento das principais concepções sobre arte e fazer artesanal, e de filósofos neoplatônicos. Esses filósofos estabeleceram as diferenças e interdependências entre arte, artesanato, ciência e técnica. Para eles, as atividades diretas sobre a natureza voltadas à reprodução da vida pertenciam ao domínio da técnica. Atividades votadas à construção de objetos, também ligados à reprodução social, seriam mais tarde entendidas como "artesanato", e agregavam algum componente de arte. Por fim, as atividades ligadas ao "espírito", sem impacto imediato no fazer concreto, seria por eles definidas como pertencentes ao domínio das relações humanas, como a poesia, a política e a filosofia.

É importante relembrar que a estrutura social grega, de onde falam tais filósofos, era fundamentada no regime da escravidão. Nesse regime, atividades manuais eram reservadas aos escravos. Os homens livres, em contrapartida, lidavam com as atividades "não-manuais", divisão que criava uma visão negativa do trabalho de interação direta com os recursos da natureza e do próprio artesão (Chauí, 2005). Gullar (1994) corrobora com a concepção de que, desde a Antiguidade, já havia a ideia de que a atividade artesanal era algo "inferior" quando comparada às demais atividades, principalmente as que se voltavam ao pensamento. Na Idade Média, porém, o trabalho artesão recebe uma nova apreciação social e cultural.

A expressão artesanal medieval foi marcada por importantes fatores sociais. Um que merece destaque, pelo seu grau de amplitude, se configura no desenvolvimento das relações servis, características da época. As relações servis estabeleciam uma vinculação direta de subordinação dos servos (arrendatários de terras) aos senhores feudais (proprietário das terras), marcando grande parte do desenvolvimento social do período medieval. Porém, graves dificuldades econômicas, a partir, sobretudo, do final do século X ao século XIII, desestabilizaram essas relações de subordinação, quando então são criadas as condições sociais e econômicas para a emergência e a fixação das atividades artesanais. $\mathrm{O}$ artesão emerge como figura relativamente independente em seu manejo da natureza e produção de bens, sendo o detentor de todo o conhecimento e do manejo produtivo (Batista, 2014).

Contudo, novas transformações iriam abalar a estrutura artesanal. Alterações políticas e econômicas que, por sua vez, marcam o fim do período medieval, levam, paulatinamente, às condições de desapropriação dos artesãos sobre seus próprios meios de produção. O fundamento da autonomia e a própria organização política profissional desse grupo também sofrem a influência de novas configurações pelas quais passou a arte, especialmente no Renascimento, quando o artesanato volta, em alguma media, a estar associado à produção/reprodução, enquanto as artes (artistas) se distinguiram pela natureza criativa de seu trabalho (Heller, 1982).

Conforme destaca Sennett (2012), a partir do Renascimento a "oficina" do artesão se prolonga, modificada, no "estúdio" artístico, sendo este último espaço valorizado por seu potencial inovador, por sua originalidade. Conforme escreve o autor, até hoje esse "contraste dá forma ao nosso pensamento: a arte parece chamar atenção sobre o trabalho único, ou, ao menos, distintivo, enquanto que o artesanato é uma prática mais anônima, coletiva e continuada (p. 87). Nesse cenário, o artista é redefinido em sua função social - agora como um "Deus criativo" (Batista, 2014). 
Por fim, a relação entre arte, artesanato, criação e reprodução é mais uma vez transformada com o advento do capitalismo. Com ele, instaura-se uma nova classe social, conforme destacamos na introdução: o trabalhador assalariado, desprovido, essencialmente, dos meios de produção e da possibilidade de planejar e executar seu próprio trabalho. As atividades artesanais perdem sua centralidade no processo de reprodução social, e o artesão cede, agora, lugar ao operário. Conforme destaca Alves (2007), o núcleo do ideário artesanal é esvaziado quando o artesão/trabalhador perde sua autonomia.

É nesse cenário, aqui brevemente resumido, que vemos os desdobramentos históricos que, partindo de um primeiro grande momento de relativa interdependência entre arte e técnica, se passa, com a transformação das relações produtivas com o capitalismo, para uma cisão entre técnica, expertise, maestria, de um lado, e um trabalhador/operário submetido à racionalidade gerencial (responsável por planejar o trabalho), de outro (Batista, 2014). Nesse contexto, o artesão se coloca hoje como um trabalhador que possui relativo domínio e controle sobre instrumentos e concepção do trabalho, mas que, inevitavelmente, tem de "dialogar" ou interagir com um mercado regido por princípios de organização capitalista - por exemplo, na própria concepção de seu produto deve levar em conta demandas que são ditadas por forças econômicas específicas.

O estudo do trabalho artesanal é importante para a psicologia do trabalho por um número de razões. Primeira, trata-se de uma categoria que se coloca entre diversos registros laborais, incluindo a informalidade, o desemprego, o trabalho precário e, paradoxalmente, o "empreendedorismo". Segunda, pois devido a essa pluralidade ou sobreposição de regimes, o artesão é uma figura, a um só tempo, de resistência, transformação e desenvolvimento de arranjos produtivos locais, com reverberações na geração de renda e mesmo "emprego". Terceira, pois, ainda que no Brasil recentemente se venha estudando com afinco as ditas profissões esquecidas (Sato, 2011), é notório que um grande volume de pesquisas tenda a seguir com investigações das questões psicossociais do trabalho formal. Quanto ao trabalho artesanal, especificamente na psicologia, as pesquisas são muito escassas, sua produção sendo mais notável nas áreas de turismo, literatura/cultura e estudos organizacionais (e.g., Faria \& Da Silva, 2017).

Sendo assim, este estudo se justifica pela importância que pode vir a ter uma melhor compreensão do trabalhador artesão para nossa apreensão dos desafios e dilemas do trabalho na atualidade, em particular do ponto de vista da produção de significados, uma ênfase pouco explorada nas pesquisas sobre o tema no Brasil (e.g., Grangeiro \& Bastos, 2018). Nesse contexto, o objetivo central desta pesquisa é descrever os processos de produção de sentidos e significados no contexto do trabalho artesanal. 


\section{Método}

O modelo teórico desta pesquisa foi desenvolvido com base em uma apropriação de elementos da base teórico-metodológica, proposta na perspectiva histórico-cultural em psicologia, refletida na Figura 1, discutida na introdução (Bendassolli \& Coelho-Lima 2015; Vygotsky, 1998). Tal modelo foi desenvolvido com a expectativa de abranger minimamente a complexidade das relações dialéticas existentes entre significados, sentidos e atividade, no contexto do trabalho artesanal (Figura 1). Busca-se articular, em torno da atividade, os processos envolvidos na apropriação dos significados sociais e em sua integração e reelaboração, por cada pessoa, a partir de seu engajamento em uma atividade concreta. Como reflexo metodológico, o modelo implica etapas distintas capazes de captar a unidade significados-sentidos (por meio de entrevistas narrativas), e também a atividade, no que se demanda técnicas que visem avançar para além do registro meramente verbal. Neste último caso, propõe-se a utilização de recursos visuais (fotografia).

\section{Procedimento de definição dos participantes}

O universo desta pesquisa engloba o conjunto de trabalhadores atuando na produção e na comercialização artesanal, especificamente no setor de transformação de matérias-primas naturais, estabelecidos na capital do Rio Grande do Norte e adjacências. A definição sobre o número de participantes foi elaborada por conveniência (Creswell \& Clark, 2013).

Como critérios de inclusão, baseados nas instruções contidas no Programa do Artesanato Brasileiro (2012), o participante deveria estar exercendo um ofício manual, transformando a matéria-prima bruta ou manufaturada em produto acabado; ter domínio técnico sobre materiais, ferramentas e processos de produção artesanal, podendo ou não contar com o auxílio de equipamentos, desde que não automatizados. O acesso a esse público se deu por meio de estratégias que envolveram contato direto em locais específicos da região, onde tradicionalmente as atividades artesanais são desenvolvidas, e ainda por meio da estratégia de "bola de neve", a partir de indicações de pessoas que se encaixassem nos critérios da pesquisa. Como resultado, a pesquisa contou com a participação de 20 artesãos. A Tabela 1 sintetiza as principais informações sobre esse conjunto de pessoas. 
Tabela 1: Características dos participantes da pesquisa

\begin{tabular}{|c|c|c|c|}
\hline $\begin{array}{l}\text { Idade / } \\
\text { Gênero }\end{array}$ & $\begin{array}{l}\text { Tempo de } \\
\text { atuação }\end{array}$ & Setor & Produto fabricado e comercializado \\
\hline 40 anos $/ \mathrm{M}$ & 20 anos & Serviços & Bijuterias com pedras comuns \\
\hline 36 anos $/ \mathrm{M}$ & 17 anos & Serviços & Lanternas de bambu e palha \\
\hline $62 \operatorname{anos} / \mathrm{F}$ & 12 anos & Serviços & Bonecas de pano \\
\hline $46 \operatorname{anos} / \mathrm{F}$ & 8 anos & Serviços & Livros infantis de EVA e tecido \\
\hline 40 anos $/ \mathrm{F}$ & 15 anos & Serviços & Esculturas com materiais reciclados \\
\hline $28 \operatorname{anos} / \mathrm{F}$ & 10 anos & Serviços & Bijuterias em aço adornadas com penas \\
\hline $60 \operatorname{anos} / \mathrm{F}$ & 20 anos & Serviços & Panos de prato rendados \\
\hline $38 \operatorname{anos} / \mathrm{M}$ & 20 anos & Serviços & Escultura em madeira com plantas \\
\hline $51 \mathrm{anos} / \mathrm{F}$ & 12 anos & Serviços & Panos de prado bordados em labirinto \\
\hline $48 \operatorname{anos} / \mathrm{F}$ & 23 anos & Serviços & Utilidades construídas com caixas e tecidos \\
\hline $66 \operatorname{anos} / \mathrm{F}$ & 14 anos & Serviços & Utilidades construídas em tricô \\
\hline $58 \operatorname{anos} / \mathrm{F}$ & 10 anos & Serviços & Esculturas em papel machê \\
\hline 40 anos $/ \mathrm{F}$ & 16 anos & Serviços & Pano de prato pintado \\
\hline $68 \operatorname{anos} / \mathrm{F}$ & 40 anos & Serviços & Roupas em tricô \\
\hline 51 anos $/ \mathrm{F}$ & 11 anos & Serviços & Jogos de banheiro pintados \\
\hline 64 anos/M & 27 anos & Serviços & Utilidades em papelão e espuma \\
\hline $44 \operatorname{anos} / \mathrm{M}$ & 5 anos & Serviços & Esculturas em garrafa PET \\
\hline 54 anos $/ \mathrm{M}$ & 30 anos & Serviços & Panos com bordado tipo Caicó \\
\hline $38 \operatorname{anos} / \mathrm{F}$ & 3 anos & Serviços & Panos pintados para cozinha \\
\hline 33 anos/F & 7 anos & Serviços & Utilidades em crochê \\
\hline
\end{tabular}

\section{Instrumentos e procedimentos}

Com base no que prevê o modelo teórico adotado, foram utilizadas duas principais estratégias de coleta de dados: a entrevista narrativa e a fotografia sobre a atividade. Quanto à entrevista, sua principal finalidade foi captar aspectos da trajetória laboral dos artesãos e incidentes importantes que pudessem nos permitir acesso à sua concepção sobre o trabalho artesanal, e o trabalho em geral (significados), bem como seu modo de elaborar os sentidos de sua atividade. A entrevista tem como alvo a captura dos elementos significativos a partir da fala, da descrição e do compartilhamento simbólico por parte do participante.

A entrevista foi desenvolvida segundo o modelo de Gioia, Corley e Hamilton (2013), que resulta no contato com os dados sem a necessidade de um elaborado aprofundamento teórico anterior, mas que não implica, necessariamente, em uma "suspensão total" da teoria. No presente caso, adotamos a sugestão de Glaser (1978), concernente à utilização de "conceitos sensitivos", isto é, eixos ou tópicos centrais em relação aos quais se pretendia obter as informações. Assim, os principais tópicos foram abordados como questões imanentes às narrativas, esperadas dentro do próprio fluxo narrativo do participante, mas, caso não fossem abordadas diretamente, elas eram retomadas ao fim da exposição. Os principais conceitos sensitivos, esperados nas narrações, se relacionam às seguintes questões: centralidade do trabalho, identificação com a atividade, origem e associação à atividade 
desenvolvida, trajetória de vida no trabalho, relações sociais, interação com o meio e o contexto, caracterização do processo de criação dos recursos, associação entre trabalho e família, comercialização dos produtos, manutenção da atividade, recursos e materiais utilizados, desenvolvimento econômico, mercado de trabalho e modelo produtivo.

Por sua vez, a utilização de recurso fotográfico visou captar elementos concretos da atividade realizada, buscando, como mencionado, complementar os elementos puramente "discursivos" das falas. Essencialmente, o processo consistiu em solicitar aos participantes que criassem imagens fotográficas (usando, basicamente, aparelhos de celular) de seus ambientes de trabalho e/ou de suas produções. A ideia era que captassem, a fim de apresentar ao pesquisador, aspectos centrais ou representativos de sua atividade. Uma vez de posse de um conjunto de fotos, os participantes, com a ajuda do pesquisador, eram auxiliados no sentido de escolher qual (ou quais) seriam as fotos utilizadas para a próxima etapa, que seria a entrevista voltada à descrição da(s) foto(s). Neste ponto, o participante explicitava os motivos da escolha desta ou daquela foto, e então passava a detalhar aspectos sobre os significados e sentidos envolvidos com aquela parte de sua atividade.

$\mathrm{Na}$ entrevista, o participante iniciava sua explanação a partir de uma questão disparadora referente à imagem selecionada por ele. Tal questão direcionava o participante a falar por quê a foto representava seu trabalho, e assim as narrativas se desenrolavam. Todas as entrevistas foram feitas no ambiente de trabalho dos artesãos que participaram da pesquisa, geralmente em intervalos da execução da atividade, programados previamente. Os encontros tiveram uma duração média de sessenta minutos, gravados, buscando captar com qualidade a maior quantidade de detalhes dispostos na interação com os participantes. O material gravado foi transcrito na íntegra, respeitando as características linguísticas e culturais presentes no conteúdo.

\section{Procedimentos de análise de dados}

As informações obtidas pelas entrevistas foram analisadas com base na técnica proposta por Gioia, Corley e Hamilton (2013), baseada em níveis de análise, culminando em um processo de generalização a partir do material empírico. No primeiro nível, a partir de uma leitura em profundidade pelo pesquisador, se buscou identificar os termos utilizados pelos próprios participantes para responderem às questões feitas pelo pesquisador, correspondentes aos "conceitos sensitivos" utilizados e descritos na seção anterior. O foco, aqui, é identificar temas ou unidades de sentido a partir das próprias nomenclaturas utilizadas pelos participantes.

Em um segundo nível da análise, caminhando para um processo de inferência e maior generalidade, foi realizada uma comparação interclasses, ou seja, entre os diversos participantes. O objetivo era captar semelhanças e pontos de convergência entre os vários tópicos, com o propósito de reduzir a quantidade de temas, iniciando o processo de categorização. Como resultado, foram elaboradas as primeiras categorias temáticas ou descritores, ainda mantendo, como referência, os termos utilizados pelos próprios participantes (apenas categorizados pela análise comparativa entre os casos). Por fim, no último nível de análise, as categorias são mais uma vez agrupadas, mas desta vez com vistas à elaboração de elementos conceituais de maior generalidade, já em diálogo com a teoria - neste caso, referente ao processo de significação. $\mathrm{O}$ "produto" gerado a partir desta etapa são categorias globais, referentes, basicamente, aos significados atribuídos ao trabalho realizado. 
No que diz respeito à análise das fotos, e sua integração com a etapa anterior, as imagens foram interpretadas a partir da tarefa inicialmente proposta aos participantes. Tendo em vista que cada um deveria produzir uma imagem que representasse seu trabalho, todos optaram por fotos que demonstravam os produtos prontos, algumas vezes em exposição para comercialização. A interpretação das imagens se associa diretamente às narrativas geradas pelas entrevistas, centrando-se sobre a concretude da atividade real e o modo próprio de relação com os elementos da atividade pelo participante (Figura 1). Desse modo, os sentidos emanam mais fortemente da produção fotográfica, que através da exposição dos recursos visuais, apontam para a caracterização dos sujeitos que os produziram, representados pelas marcas, particularmente inseridas em cada produto, advindas das mãos envolvidas na materialização criativa.

\section{Resultados e discussão}

Os resultados serão apresentados a partir da articulação entre a análise das entrevistas narrativas, submetidas ao processo de redução contínua, e a produção fotográfica, disparadora das falas e organizadora do conteúdo apresentado pelos participantes. Começamos apresentando o conteúdo que produz as generalizações, entendidas dentro do processo como sustentadoras da apropriação de significados compartilhados pelo coletivo de trabalho investigado. Em seguida, segue o conteúdo da análise das fotos, buscando evidenciar a associação entre os sentidos, fundidos na construção dinâmica da atividade, e os significados, em sua relação dinâmica e inseparável, embora individualmente mantendo suas sutilezas teóricas.

\section{Os significados do trabalho artesanal}

Iniciando pelo processo de redução contínua, técnica utilizada para a análise das narrativas, seguindo o modelo de Gioia, Corley e Hamilton (2013), foi possível identificar 168 conceitos, dispostos nas 20 entrevistas realizadas. Conforme critério descrito anteriormente, a associação dos conceitos possibilitou a configuração de 10 categorias temáticas, sendo elas: Vida (22 conceitos), Tradição (9 conceitos), Artesão (24 conceitos), Criação (27 conceitos), Trabalho (39 conceitos), Resultado (12 conceitos), Fiscalização (6 conceitos), Conflito (10 conceitos), Colaboração ( 7 conceitos) e Relações (12 conceitos).

O manejo da associação conceitual e, posteriormente, da associação temática, resultou no desenvolvimento de três dimensões globais, pelas quais podemos apreender, num primeiro momento, os "significados" envolvidos com a atividade artesanal - isto é, os aspectos gerais, coletivos e compartilhados desta atividade. No próximo bloco de resultados, veremos como eles se articulam, pela atividade, aos sentidos, trazendo aspectos mais idiossincráticos à análise. As três dimensões são descritas a seguir.

- Dimensão 1. "Uma vida de tradição". Originária da associação das categorias temáticas "vida" e "tradição", essa dimensão global apresenta o significado do trabalho como articulado intimamente à própria dinâmica familiar;

- Dimensão 2. "O artesão que trabalha e cria resultados". Originária da associação das categorias temáticas "artesão", "criação", "trabalho" e "resultados”, essa dimensão global reflete uma percepção própria do trabalhador artesanal, construída por intermédio das ações que desenvolve, discutindo a elaboração de cada prática laborativa através do manejo e articulação das ferramentas de execução da atividade, e compreendendo as consequências, esperadas ou não, como retornos do trabalho. 
- Dimensão 3. "Relações fiscalizadas de colaboração e conflito". Originária da associação das categorias temáticas "fiscalização", "conflito", "colaboração" e "relações", essa dimensão global aponta o desenvolvimento das várias relações necessárias para a realização do trabalho artesanal, abordando seus principais benefícios e conflitos, e a articulação entre os atores e instâncias sociais de controle e regulação do trabalho.

Em termos gerais, a primeira dimensão descreve significados que apresentam o trabalho em sua íntima relação com a vida do trabalhador, em particular com a família. No caso do artesão, cada grupo familiar também se torna grupo de trabalho, e a perpetuação do manejo e das práticas, distintivas e particulares da atividade, deve ser assegurada de modo a permitir a continuidade intergeracional. O significado, neste ponto em que se examina sua dimensão coletiva, está ancorado na história do grupo familiar, cuja atividade, por vezes personificada em um membro presente ou passado da linhagem, é concebida a partir de narrativas geracionais, e também com a transmissão de saberes e fazeres. Ainda no plano dos significados, esta dimensão aponta para a íntima conexão atividade-identidade. O Quadro 1 traz algumas falas ilustrativas desta dimensão.

A segunda dimensão agrega as unidades temáticas que apresentam o significado do trabalho como ligado ao domínio técnico, em linha do que destaca a bibliografia consultada, em especial Sennett (2012) e Batista (2014). A originalidade do processo de concepção e produção da peça artesanal é apresentada como um elemento chave na caracterização do produto, e os artesãos apontam isso como um elemento distintivo do trabalho, que promove valor e credibilidade aos resultados que se alcançam. Um operador teórico que pode nos ajudar a compreender esse aspecto do significado do trabalho para os artesãos é o de "trabalho bem-feito", proposto na clínica da atividade (Clot, 2008). Trata-se de uma forma de relação com a atividade em que seu significado deriva, em parte, da análise feita pelo trabalhador com respeito à qualidade do que está sendo feito. Os critérios para a avaliação dessa qualidade, segundo Clot, provém do gênero profissional - a história de um determinado metiê, a qual é passada de geração a geração de trabalhadores. Do ponto de vista da organização da atividade artesanal, com elementos que, como dito na introdução, apontam para arranjos "pré-capistalistas", tal forma de apreciação do trabalho é condizente com um controle social do trabalho, na ausência de registros formais ou institucionalizados de produção de julgamento de valor (como a existência de um gestor ou "chefe", em uma organização tradicional de trabalho, por exemplo). Embora haja, no final do processo, um cliente que pode, ou não, comprar um determinado produto, sua concepção e execução ocorre no contexto de um saber de metiê, que informa o trabalhador sobre a qualidade e, sobretudo, o sentido do que está sendo feito.

Por fim, a terceira dimensão agrupa temas sobre os significados do trabalho derivados das relações interpessoais e com agentes do Estado. Como em qualquer outro trabalho, essa dimensão é um aspecto-chave da significação do trabalho, mas que, no caso do artesão, ganha contornos mais específicos, na medida em que a atividade é, fundamentalmente, coletiva, além de integrada em redes de relações primárias, como é o caso da família. No Quadro 1 também podem ser visualizadas frases ilustrativas para estas duas últimas dimensões. 


\section{Quadro 1: Frases representativas das dimensões globais de análise}

\begin{tabular}{|c|c|}
\hline \multirow{2}{*}{$\begin{array}{l}\text { Dimensão } 1 \\
\text { Uma vida de } \\
\text { tradição. }\end{array}$} & $\begin{array}{l}\text { "Passei } 20 \text { anos trabalhando em circo, o meu pai era circense, a família } \\
\text { toda. Meu pai era artesão também, e quando nós chegávamos em uma } \\
\text { cidade com o circo ele ia vender artesanato nas feiras também, o artesa- } \\
\text { nato já vem de família, eu trabalho com artesanato a mais ou menos uns } \\
30 \text { anos, eu faço mais coisas do que meu pai fazia, trabalho com escultu- } \\
\text { ra, faço pintura em quadro, faço colares e acessórios, e hoje eu vivo só } \\
\text { do artesanato (...)”. (P.1) }\end{array}$ \\
\hline & $\begin{array}{l}\text { “(...) esse é um material que eu e meu marido desenvolvemos e nós for- } \\
\text { necemos para vários lugares, então esse trabalho nos fez bem conheci- } \\
\text { dos. Também somos conhecidos por que isso aí vem também de família, } \\
\text { o pai do meu marido e o meu cunhado já fazem isso há muitos anos, só } \\
\text { que com outros materiais, aí começamos a fazer do nosso jeito, então } \\
\text { isso envolve toda a família e a gente fica bem conhecido. (...)” (P.2) }\end{array}$ \\
\hline \multirow{2}{*}{$\begin{array}{l}\text { Dimensão } 2 \\
\text { O artesão que } \\
\text { trabalha e cria } \\
\text { resultados. }\end{array}$} & $\begin{array}{l}\text { "Eu sou ar tesã, e o nome artesão já diz tudo, é o que faz, é o que cria, não } \\
\text { é só você pegar uma peça e copiar uma coisa que você vê na internet pra } \\
\text { fazer igual, não! Você tem que criar! Eu acho que é isso, o artesão tem } \\
\text { que criar, você tem que ter mentalidade pra inovar.” (P.3). }\end{array}$ \\
\hline & $\begin{array}{l}\text { "O meu artesanato é aquilo que eu mesmo faço, aquilo que a gente cria, } \\
\text { uma coisa que você não sabe, mas aprende a fazer. Ai você monta, e no } \\
\text { final consegue fazer aquela obra. Como eu sou artesão eu pego uma peça } \\
\text { assim e crio uma arte, pego uma coisa como uma pedra, um pedaço de } \\
\text { madeira, e crio uma obra dali, você usa a criatividade." (P.4). }\end{array}$ \\
\hline \multirow{2}{*}{$\begin{array}{l}\text { Dimensão } 3 \\
\text { Relações fis- } \\
\text { calizadas de } \\
\text { colaboração e } \\
\text { conflito. }\end{array}$} & $\begin{array}{l}\text { "Ser artesã, até o momento pra mim é uma profissão ingrata. Porque } \\
\text { existe entre os próprios colegas de arte uma rivalidade, um achando } \\
\text { que o outro vai tomar sua frente, aquela competição sem nexo, porque a } \\
\text { minha arte é uma, a dele é outra, todos tem sua arte, ninguém tem nada } \\
\text { igual, você não faz nada igual. Mas aos poucos eu tenho a esperança } \\
\text { dessa rivalidade tornar-se em nada, e a gente procurar ter mais união } \\
\text { pra conseguir coisas melhores do que nós temos agora." (P.5). }\end{array}$ \\
\hline & $\begin{array}{l}\text { "A maior dificuldade é quando o comprador vê a arte e não dá o valor } \\
\text { que ela tem, sempre acha que é tudo muito caro, acha que poderia ser } \\
\text { mais barato, não procura analisar o esforço que a gente faz, a energia } \\
\text { que a gente gasta fazendo aquela peça com carinho, pra ser vendida. As } \\
\text { vezes, aparece um atravessador, que a gente pede um preço como esse, aí } \\
\text { ele quer comprar por menos de } 50 \% \text { desse valor, aí eu digo que faço por } \\
180 \text { reais, aí ele me pede pra tirar os } 100 \text {, ai veja só, uma obra dessa, que } \\
\text { me deu trabalho, eu posso vender por } 80 \text { reais? A dificuldade da gente é } \\
\text { essa, de o público em geral não valorizar a arte do artesão." (P.6). }\end{array}$ \\
\hline
\end{tabular}




\section{A mobilização significados-sentidos pela atividade}

Como mencionado anteriormente, todos os participantes optaram por fotos de seus produtos prontos, como sendo representativas de suas atividades de trabalho. Conforme destaca Engeström (1987), e outros teóricos das teorias da atividade aqui utilizados, o objetivo da atividade, seu produto, é a razão de ser da atividade, e é no encontro com esse produto (síntese complexa de elementos humanos e técnicos) que se produz o sentido da atividade, a concretização de seu motivo. Não é, pois, surpreendente que os artesãos tenham optado por mostrar seus produtos quando instigados a falar sobre sua atividade e seu sentido. A seguir, destacamos três dessas imagens.

Figura 2: Imagem disparadora: Esculturas em papel machê

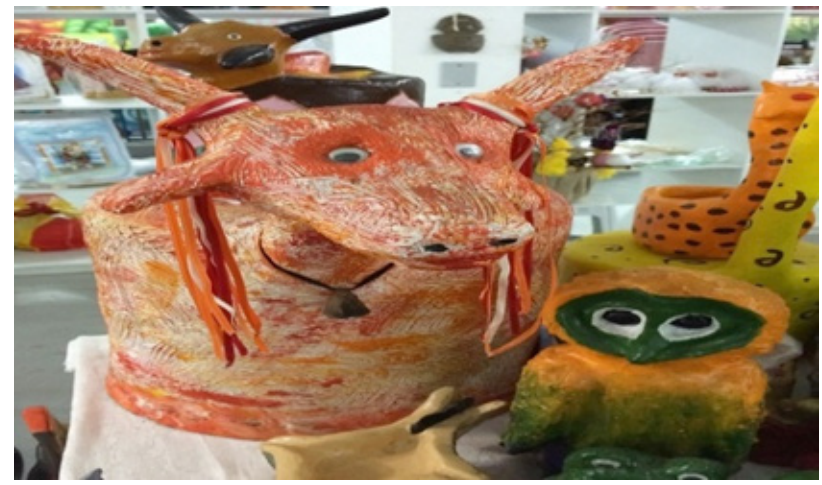

Figura 3: Imagem disparadora: Luminárias de bambu e sisal

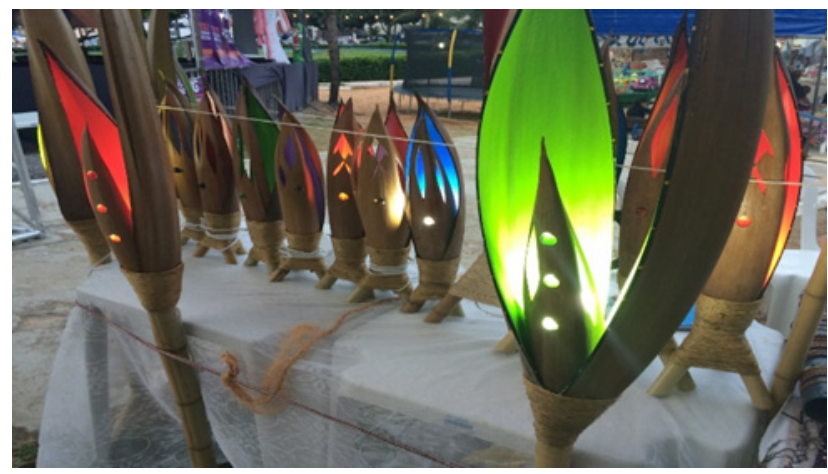

Figura 4: Imagem disparadora: Escultura de jardim

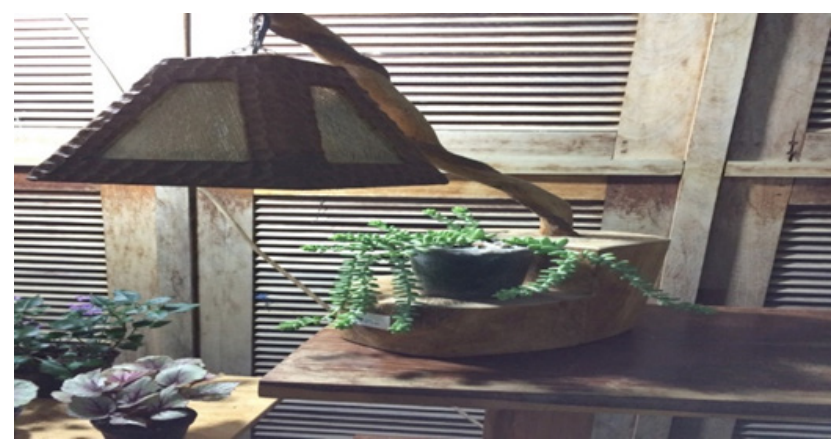


As fotos evidenciadas revelam o manejo criativo de uma diversidade de recursos próprios da região onde os artesãos estão instalados. Como ferramenta de estímulo às narrativas, tais imagens eram fortemente exploradas nas narrativas a partir da demonstração de como o produto conferia ao participante o título/status de artesão. A forma como ele realiza a atividade e os resultados obtidos com o produto legitimam o seu papel, sendo o produto o suporte concreto sobre o qual converge o reconhecimento pessoal e social (compra do produto).

Mesmo quando se tem um "mesmo" produto entre dois artesãos, os caminhos para sua elaboração são distintos, e revelam o que os participantes sugerem como "filosofia própria de trabalho", e que, em termos teóricos, consiste da materialização, via experiência, de um processo de trabalho e de significação deste último que trazem as marcas da singularidade. A fala de um dos participantes (P8) ajuda a ilustrar este ponto.

Ser artesão, pra mim, é pegar a matéria prima, seja ela de qualquer reino, vegetal, animal ou mineral, e transformar com as próprias mãos em arte, sem nenhuma intervenção de materiais industrializados. Eu uso o que tenho à minha disposição, às vezes eu estou em um lugar e vejo algo que me dá uma ideia, às vezes em uma conversa eu tenho uma ideia, eu acho que isso é criatividade, e quando eu sou criativo eu sou também exclusivo, minha ideia é só minha, minhas peças são únicas, você não encontra isso em lugar nenhum, e por isso elas tem valor. (P8, p. 8)

A criatividade é colocada como um recurso que dota a atividade de sentido, tornado a experiência do trabalho um complexo fenômeno multifacetado, sobre o qual o sujeito empreende essencialmente um nexo lógico firmado na coerência de suas identificações, que podem se ligar aos recursos, práticas e produtos da atividade. É importante notar também que a ação criativa, para além de uma prerrogativa que constitui a identidade do que é ser artesão, se apresenta como um modo de caracterização do próprio trabalho. Entre as etapas do ciclo de produtivo artesanal, o uso da criatividade é um fator distintivo que passa a conferir ao próprio trabalho o sentido e o valor de um verdadeiro artesanato - conferindo ao seu produtor, em contrapartida, a possibilidade de ser reconhecido como um "verdadeiro artesão".

Concretamente, na construção da significação do trabalho, existe um conjunto de determinações que legitimam o que é ou não artesanato, e, por conseguinte, quem é ou não artesão. A ausência do elemento criativo gera uma forte tensão que diz respeito à própria identidade daquele que trabalha. Tal tensão se configura na seguinte questão: Se tais ações, tomando aqui o exemplo da exigência pela criatividade, são fatores fundamentais para o desenvolvimento do trabalho artesanal "verdadeiro", a prescrição de um conjunto de normas que expressam o "como fazer" não limitaria a própria ação criativa? Em outras palavras: devido a pressões de "mercado", a prescrição por um (único) tipo de produto ou abordagem, estaria o artesão fadado a repetir a história, na qual a oficina se distancia do ateliê, não só em termos da criatividade "agregada", mas em termos das constelações sociais e de valores que separam ambos esses espaços de trabalho criativo (Sennett, 2012).

Loup e Rakotovahiny (2010) discutem os contrassensos do fazer artesanal apontando que a criatividade é um símbolo de extrema valorização dessa atividade. Para esses autores, os artesãos não abrem mão, ao menos não sem tensão e conflitos, do elemento criador-criativo porque este reflete os fatores que dão sentido (razão, motivo) à atividade como 
um todo. Isso também nos remete ao fato de que o trabalho manual (no estrito sentido de algo "reprodutivo", manejo mecânico ou movimento físico) é insuficiente para a obtenção da qualidade nos produtos criados, mesmo que estes sejam feitos em grande quantidade.

A última ideia remete a outro dilema ou tensão mencionada na introdução: o quanto a reprodutibilidade, a mera aplicação de um saber "técnico" (Gullar, 1994) com vistas a se gerar grande volume de produtos "similares" para se vender no mercado, pode minar a atividade artesanal ou então transformá-la em um trabalho precário ou em um subemprego a serviço de redes de consumo com objetivos alheios ao artista e à sua família. Os resultados deste estudo mostram que, mesmo na "reprodutibilidade", o elemento de criatividade e "autoria” é buscado e visado como elemento gerador de sentido. A “implicação pessoal” no trabalho (Perrenoud, 2012) é, ao lado da criatividade, um dos núcleos geradores de significação para essa atividade, e, ao mesmo tempo, sua fonte potencial de conflito e tensões, haja vista a inscrição do artesão em circuitos de reprodução de mercadorias muitas vezes tratadas como commodities. Se os elementos intrínsecos que permitem a manutenção dessa implicação forem abalados, então é de se esperar que o próprio sentido da atividade seja perdido. Neste caso, apenas seu "significado" permaneceria, se tanto: significado de atividade geradora de "produtos culturais".

\section{Considerações finais}

A pesquisa empreendida foi idealizada e construída buscando discutir algumas vivências de trabalhadores artesanais por meio da compreensão de alguns elementos do processo de significação do trabalho. Seu modelo de base se consistiu por meio da discussão de como os participante elaboram a relação entre significados e sentidos do trabalho, expressa pela prática da atividade e construção do artefato artesanal.

A questão norteadora, em torno do processo de significação, foi sendo elucidada em três etapas. Na primeira, a identificação realizada nas entrevistas trouxe à tona uma série de significados, representados pelos conceitos destacados das histórias que foram apresentadas. Também durante a identificação conceitual, os sentidos do trabalho se fizeram presentes, principalmente expressos nas explicações de cada conceito, que explicitaram as peculiaridades de cada indivíduo na interpretação do signo que se difunde socialmente em larga escala. Essa interpretação particular aponta a apropriação desenvolvida pelos artesãos que consideram as suas próprias experiências e vivências, pessoais e da atividade, para dar sentido às ações que desenvolvem, atribuindo valores e juízos aos conceitos que discutiam nas narrativas.

O manejo da associação conceitual e, posteriormente, de associação temática, resultou no desenvolvimento de três dimensões globais sobre as quais os sentidos do trabalho artesanal investigado expõem suas características, sendo possível também retratar as tensões existentes no cerne de seu desenvolvimento. O uso dessa técnica ajuda a enfatizar sua relevância em termos de sua possível contribuição para a discussão dos processos de significação ao apreendê-lo a partir de estruturas intrinsecamente relacionadas, evidenciando a necessidade de aproximação das experiências particulares dos participantes. Entendemos que o artesanato constitui uma forma potente de enfatizar os aspectos "orgânicos" do trabalho, para além de sua institucionalização como emprego. Em outras palavras: o trabalho artesanal revela sua impregnação por práticas que envolvem narrativas familiares, narra- 
tivas culturais locais, mobilizando a construção de produtos, ao mesmo tempo com valor econômico, mas também simbólico. Os aspectos orgânicos desse trabalho o remetem ao "mundo da vida" do trabalhador, a seu espaço-casa (e não, necessariamente, ao espaço da "fábrica" ou do "escritório"), desvelando, inclusive, sua faceta de reprodução da vida social, como trabalho de subsistência cooperada.

A partir disso, é possível compreender que o sujeito que constitui suas práticas laborativas no exercício da "manualidade criativa" está, a todo tempo, se reinventando, seja por necessidade, seja pelo poder adaptativo do fazer artesanal, constituindo um microuniverso repleto de saberes, que se apresentam para aqueles que lançam, sobre ele, um olhar inquieto e interessado.

\section{Referências}

Aguiar, W. M. J. \& Ozella, S. (2006). Núcleo de significação como instrumento para a apreensão da constituição dos sentidos. Psicologia Ciência e Profissão, 26(2), 222-245.

Alves, G. (2007). Dimensões da reestruturação produtiva. Londrina, PR: Práxis.

Araújo, V. S. (2014). Tempo de (re) criação. Dissertação de Mestrado, Programa de Pós-graduação em Psicologia, Universidade Federal do Ceará, Fortaleza, CE.

Batista, A. (2014). Processos de trabalho: da manufatura à maquinaria moderna. Serviço Social \& Sociedade, 118, 209-238.

Bendassolli, P. F. \& Coelho-Lima, F. (2015). Psychology and informal work: the meaning-making perspective. Psicologia \& Sociedade, 27(2), 383-393.

Bendassolli, P. F. \& Gondim, S. M. (2014). Significados, sentidos e função psicológica do trabalho. Avances en Psicologia Latinoamericana, 32, 131-147.

Bulgacov, Y. L. M., Camargo, D., Canopf, L., Matos, R. D., \& Bevervançozdepski, F. (2014). Contribuições da teoria da atividade para o estudo das organizações. Cadernos EBAPE, 12(3), 1-20. Chauí, M. (2005) Convite à filosofia. São Paulo: Ática.

Clot, Y. (1999). La fonction psychologique du travail. Paris: PUF.

Clot, Y. (2008). Travail et pouvoir d'agir. Paris: PUF.

Creswell, J. W. \& Clark, V. L. P. (2013). Pesquisa de Métodos Mistos. Porto Alegre: Penso.

Engeström, Y. (1987). Learning by expanding. Helsinki: Oriental-Konsultit.

Faria, A. R. \& Da Silva, A. R. L. (2017). Artesanato nos estudos organizacionais: a literatura brasileira de 2006 a 2015. Revista Pensamento Contemporâneo em Administração, 11(2), 120-135. Gioia, D. A., Corley, K. G., \& Hamilton, A. (2013). Seeking qualitative rigor in inductive research. Organizational Research Methods, 16(1), 15-31.

Glaser, B. (1978). Theoretical sensivity. Mill Valley, CA: Sociology Press.

Grangeiro, R. R. \& Bastos, A. V. (2018). O significado do trabalho para artesãos da região do Cariri Cearense. Holos, 34(2), 190-206.

Gullar, F. (1994). O artesanato e a crise da arte. Revista de Cultura e Vozes, 88(4), 7-12.

Heller, A. (1982). O homem do Renascimento. Lisboa: Presença.

Leontiev, A. N. (1978). O desenvolvimento do psiquismo. Lisboa: Livros Horizonte.

Loup, S. \& Rakotovahiny, M. A. (2010). Protection et valorisation de la créativité artisanale. Management et Avenir, 10(40), 100-115.

Marx, K. (1989). O Capital. Rio de Janeiro: Bertrand.

MOW [Meaning of Work International Research Team]. (1987). The meaning of working. London: Academic Press. 
Oliveira, G. S. (2010) Artesanato: criatividade, informalidade e trabalho. In III seminário nacional de trabalho e gênero, UFG. Unicamp. Recuperado de http://strabalhoegenero.cienciassociais.ufg.br/up/245/o/GERUZA.pdf

Perrenoud, M. (2012). Éditorial. Entre l'art et le métier, l'émulsion symbolique. Opus, 21, 9-18. Ribeiro, C. V. S. \& Léda, D. B. (2009). O significado do trabalho em tempos de reestruturação produtiva. Estudos e Pesquisas em Psicologia, 4(2), 76-83.

Sato, L. (2011). Psicologia e trabalho: focalizando as "profissões esquecidas". In Psicologia social e seus movimentos: 30 anos de ABRAPSO. Recife-PE: ABRAPSO.

Sennett, R. (2012). O artifice. Rio de Janeiro: Record.

Vygotsky, L. S. (1998). A formação social da mente. São Paulo: Martins Fontes.

\author{
DANIEL SANTOS DE CARVALHO \\ http://orcid.org/0000-0001-5248-7402 \\ Mestre em Psicologia pela UFRN. \\ E-mail: daniel.scarvalho@unp.br
}

\title{
PEDRO BENDASSOLLI
}

http://orcid.org/O000-0002-7761-0857

Doutor em Psicologia pela USP.

E-mail: pbendassolli@gmail.com

\begin{tabular}{ll}
\hline Histórico & $\begin{array}{l}\text { Submissão: 16/06/2017 } \\
\text { Revisão: 26/10/2018 } \\
\text { Aceite: 25/02/2019 } \\
\text { Concepção: DSC; PB. } \\
\text { Coleta de dados: DSC. } \\
\text { Análise de dados: DSC. } \\
\text { Elaboração do manuscrito: DSC; PB. } \\
\text { Crítico revisões de conteúdo intelectual importante: PB. } \\
\text { Final aprovação do manuscrito: DSC; PB. }\end{array}$ \\
\hline $\begin{array}{l}\text { Financiamento } \\
\text { Consentimento de uso de }\end{array}$ & Não houve \\
\hline $\begin{array}{l}\text { imagem } \\
\text { Aprovação, ética e } \\
\text { consentimento }\end{array}$ & Foi obtido o consentimento escrito dos participantes. \\
\hline
\end{tabular}

